\title{
ONLINE CLASSES IN MUSICAL CULTURE FOR GENERAL-EDUCATION HIGH-SCHOOL STUDENTS IN MOODLE LMS
}

\section{VALIDA TVRTKOVIĆ-AKŠAMIJA}

\begin{abstract}
Distance learning can be equally successful as the traditional classes, if appropriate teaching methods, technologies, etc. are applied. This paper is aimed at presenting the prospects of developing, managing, and assessing the online teaching process using the web application Moodle LMS in the musical culture classes in a general-education high school, the way in which students acquire knowledge, and what their role is in online classes using Moodle LMS.
\end{abstract}

Key words: online classes, musical culture in general-education high schools, Moodle LMS, learning and distance-learning classes.

\section{Introduction}

Introduction of technologies that allows online communication is not the only prerequisite for improving learning. "The Internet introduces to dictionaries a new term for learning, web-based learning, i.e. online learning - Online learning is classified as a comprehensive term that pertains to computer and internetaided learning. Levels of such learning vary, starting from the basic software that include text and graphics, exercises, testing and recording results - such as test results, up to high sophistication. Sophistication may also be included as animations, simulations, audio and video sequences of discussion groups with peers and experts, online mentorship, links to materials stored on the internet or the web, and other educational resources. Together with online learning ${ }^{1}$, the term 'online' education was formed.' (Kljakić, 2006, 6) Any form of distancelearning and teaching where one or more electronic devices is used as a means of communication, distribution and instruction is called e-learning. What distinguished online classes from e-learning is the fact that online classes use only the technologies that allow online communication in real time, which is typically possible only using computers networked into one or more computer networks, while e-learning uses any electronic technology; including computers, television, radio, phone, mobile devices, satellites, etc. Advance in technology allows the participants in the teaching process to use synchronous and asynchronous learning

1 Terms related to online learning are "web-based learning", technology-based learning and, since recently the most frequently used term is "e-learning". 
tools in classes, as well as various web applications aimed at learning and managing distance teaching such as Moodle, Blackboard, Design2Learn, Claroline, etc.

What is essential and the most specific for such form of education is the fact that it is an educational process where the teacher and the student are geographically separated and therefore the face-to-face communication is impossible; communication proceeds using one or more technological media, typically electronic ones (interactive television, satellite television, cable television, computer, telecommunications, etc. (Guthrie, 2002, 591)

Asynchronous learning tools allow students to independently select contents and relate them to other documents according to their own education, and use discussion groups, e-mail, blog, wiki, etc. for interaction with the teacher. The advantage of asynchronous learning tools is the possibility of studying contents at any time and any place, but its disadvantage is getting the feedback in delayed time (messages are posted at any time, while they are read and replied to by other users at the time which is convenient for them; in other words, users are not necessarily online at the same time, as they have to be in case of synchronous exchange).

Synchronous tools allow communication, both between teachers and students, and among students, in real time. Feedback is obtained in real time, which implies presence and activity of all the participants in the teaching process, including that of the teacher. This way of learning typically happens with all the participants gathered at the same point in time using Internet sites, chat-session, blog, virtual classrooms, discussion rooms, using internet telephony and twoway audio and video conferences. The task of online classes is the commitment to develop challenging activities that allow students to tie new information with the old one, to adopt the new meaning and use their cognitive abilities, since it is the teaching strategy, rather than technology, that affects the learning quality.

\section{Characteristics of online classes}

Although technology plays the key role in online classes, teachers must be trained in the new organization of classes so as to give guidelines to students and thus make distance classes effective enough. The same as in classic classes that take place in the classroom, online classes teacher is primarily an intermediary between the content and the students. In both cases, teacher's goal is to successfully transmit knowledge and skills in given field to students. Nevertheless, due to the conditions of delivery, the methods and ways of teaching are not necessarily the same. In modern teaching methodologies we will look for the teaching methods which allow students to acquire knowledge and skills with more ease and with a higher quality. Since in online classes there is no direct interaction between the 
teacher and a student or among the students, many methods and ideas have to be adjusted to online teaching conditions.

Goals and tasks of online teaching for any given unit to be delivered are accurately defined, while the students are, all the time, aware of the subject matter they would learn or skills they would acquire. Besides the reasons such as cost-effectiveness, possibility to overcome physical distances, etc., the reason for and simultaneously the benefit of using and attending online classes as a form of distance education, is the possibility of teacher to include all students in teaching processes. Such a prospect is allowed by online collaboration tools such as chat, discussion forums, etc. The use of forum, chat, and other kinds of collaboration tools can also help "shy" students to express their ideas and thoughts in the virtual online environment (Porter, 2004, 35).

Students in online classes can access the content, and work on it at any time. The dynamics of online educational process requires accurate definition of rules. Online classes are mostly based on students' activity and their collecting and organizing educational content. In this process, teachers guide, direct, and refer them to additional sources of information. With such a way of work and learning, where students have both a great freedom and responsibility too, due dates for individual contents, topics, assignments and exams need to be well defined. Communication and approach to classes is mostly based on textual interaction, if we exclude video-conference transmissions, which requires a great focus and flexibility in work both from teachers and students.

\section{Teacher's role in online classes}

Historically, the teacher has undergone various forms of class organization. In all ages, it was only the form of classes that changes, while the teacher's function - i.e. upbringing and educating students' personalities has remained the same. Innovations in music education play a significant role in the world, though not sufficiently in our country. Application of innovations is a necessary task for any modern school teacher.

At present, teachers in all courses, including the musical culture ones, are expected both to have the necessary general culture, professional and pedagogical qualifications, and to be able to accept new discoveries, apply, and make an effort to further develop and advance them. Network resources and technology, primarily the Internet, condition the emergence of new kinds of teaching, learning and education. Internet in education has become an inexhaustible source of information, as well as a communication tool and means of learning. On the other hand, Internet as a medium, means of communication, learning and teaching, opens possibilities for using new, prominently efficient methods for teaching new generations. 
The teacher had the obligation to expand students' knowledge, enable them to participate in society on an equal footing, and to develop students' nobleminded characteristics with various upbringing activities. In the traditional classes, teachers managed teaching contents being studied by using textbooks and media/resources. They were expected to have the ability to present the teaching contents, to teach, be responsible for students' advancement and be able to assess the advancement thereof.

Efficient online classes require for thorough preparation of educational material and technical support, and a detailed study of students' profiles and characteristics. Online teachers' competence depends on their knowledge and experience in many fields. They help student in the selection, collection and organization of the content, guide and assess students during learning, and encourage them to achieve the best results possible. Such a person must possess pedagogical, communication and organization skills and high professional competence, since distance learning requires great expertise and ability of teachers involved in it.

Online classes do not decrease the teacher's function; rather, through various tasks, the teacher is still an irreplaceable factor of education and upbringing. The teacher plays the central role in every form of teaching and learning; he or she takes an active role and responsibility for education results. Teachers in online classes perform the following functions:

- the function of organizer and implementer: they select, prepare and use forms and methods of teaching activity, as well as teaching resources and technical aids for the delivery of educational process;

- the function of planning: they select, analyze and distribute teaching contents, i.e. develops annual and thematic plans, and plans for individual teaching units;

- the function of programmer: they define the extent and depth of teaching contents (didactic transformation of scientific, artistic, technical and technological contents into teaching ones), and adjust them to students' abilities;

- the function of leader: they organize, deliver, lead and guide the teaching process;

- the function of a diagnostician and a verifier: they evaluate flows and results of teaching work, i.e. track, examine and assess students' work and performances.

A particular importance in online classes is bound to the intensity and quality of the communication between the teacher and students. With the way and frequency of online communication, the teacher let the students know that they do not talk with an electronic device but that he/she is a real person who guides 
them and help them in their studying. During online classes communication between teachers and students is diverse. It is initially based on greetings, getting to know each other, and instructions. A classes proceed and expand in terms of content, communication focuses on clarification of tasks, instructions for accomplishing them, support and motivation for success.

Teachers use feedback to keep in constant touch with students and this way obtain information on how well students get along in online classes, their successes, way of learning and queries. In this way teachers help and enable students to complete online education in line with their abilities and as successfully as possible. Assessment of students' knowledge in online education encompasses monitoring on several indicators which are, at the end of online education, wrapped up in a single whole, in regards to the respective values observed. During online classes, teachers record students' activity. It is the most prominent in the interaction between students and teacher, and among students. Naturally, it pertains to information closely related to the content and topics of individual exercises, assignments and seminars. Besides, teachers assess communication among students, which includes exchange of experiences, ideas and support related to online classes. Depending on the content of online classes, the assessment system includes application of essay papers, problem tasks, and final exams. In this case, teachers advise each student about the way in which they should view the tasks, define problems, and solve them successfully. Online classes are a high-quality education process where teachers and students actively cooperate with the aim of achieving the given educational goals. In doing so, they intensively use information and communication technologies for creating adjustable virtual environment where they develop and use multimedia interactive educational materials, practice mutual communication and cooperation, while students complete individual or group tasks and projects and conduct continuous self-assessment and knowledge assessment.

\section{Advantages of online classes}

Online classes are not a "magical ball" which will replace and put out of use the existing pedagogical theories, principles and norms. In this sense, online classes will not eliminate the existing methods and technologies; rather, it must be an appropriate and proper complement to those.

In the formal sense, online classes include a number of learning strategies and technologies that support learning, such as CD-ROM devices and media, classes based on computers, video-conference system, teaching contents for learning delivered using the satellite communication and virtual learning networks. In other words, it is not only the web-based teaching or distance learning; on the contrary, it includes many avenues for individual information exchange and 
knowledge acquisition by participants in the process. In general, such learning is based on electronic technology, and is shaped in a way that allows acquisition of knowledge both for students in the formal learning and teaching process, and for all categories of participants in the so-called lifelong learning and teaching process, which includes learning for working people, retraining for new occupations, etc.

Online classes also have a number of significant advantages over the traditional classes, as follows:

- lifelong learning, professional advancement;

- the place of learning is selected depending on the method used for learning;

- participation in highest-quality or the most prestigious programs;

- selection of one's own way and pace of learning;

- using various technologies, additional knowledge and skills are acquired besides the information on what is being learned;

- teachers too have the possibility to learn from students who independently look for the source of information.

Besides the described advantages of online learning over a traditional one, there are other advantages as well. Online environment offers a greater possibility for reasoning and refining ideas, more students' control over materials, flexibility endorsed by unlimited access to materials and an improved level of interaction with the material itself, as well as in the form of possibility for active learning through conferences, discussion groups and collaborative projects.

\section{Disadvantages of online classes}

Since its first application in the teaching process, online classes have faced strong criticism, which is fully justified since a great number of pedagogically and didactically poor applications appeared within teaching over the Internet. The weakness of such applications is that system of teaching is methodologically speaking, conceived and elaborated rather poorly. Online classes are also characterized by "the geographical or the temporal distance, or both -geographical and temporal distance" depending on the communication media used, (Tinio, 2002, 6), while Moore (2003, 30) also emphasizes the "educational and psychological distance between teachers and students".

One of disadvantages of online classes is the impossibility of individual approach to students due to physical, i.e. geographical separation, then the possibility of cheating during online tests, poorly aligned educational contents with teaching methods and available technology, and the impossibility of live contact. Teachers in online classes cannot watch their students neither see nor interpret expressions on their faces. 
The listed disadvantages of online classes prompted online course designers to include a greater number of experts in various professions in developing both the code architectures of the used teaching software and creating contents and methods for distributing the content.

A significant breakthrough in overcoming the listed disadvantages of online classes was achieved by including experts for teaching, methodologists, and teachers/professors in designing educational contents and teaching methods. With the emergence of $\mathrm{CMS}^{2}$ and $\mathrm{LMS}^{3}$, which did not focus solely on content or technology but rather on the participant in online classes, the situation changed dramatically.

\section{Web-application Moodle LMS}

When the process of designing online programs include both software engineers and web designers on the one hand, and teachers who are familiar with the methodology of (traditional) teaching, dynamic web applications appear aimed at the organization, delivering and evaluation of distance-managed teaching processes. A great number of web applications appeared designed for managing the processes of learning and distance-teaching, both free-of-charge and commercial, with different licenses for use, written in various languages and for different server platforms. However, the existence of a great number of web applications did not solve the problem of distance education. The use of many web applications in distance classes produced poor educational effects, which prompted researchers, teachers, web-programmers and graphic designers to devote more attention to the way of integrating teaching methods in technology use. As a response to the problem of poor educational power of such applications web application Moodle LMS was developed - a modular, object-oriented web application designed for managing distance learning and teaching processes. The advantage of Moodle over other web applications is primarily reflected in the fact that it is focused on learning and teaching processes, rather than on the used technology.

Using Moodle LMS, teachers can successfully include teaching methods in the distance-managed educational process, which prompted us to devote attention to Moodle $\mathrm{LMS}^{4}$ in this paper, as to the one of the most popular dynamic web applications with the possibilities for teaching in online classes.

2 Abbreviation CMS is used fir the phrase "Content Management system".

3 Abbreviation LMS is used in distance learning for teh phrase "Learning Management System", in librarianshio for Library Management System, as web application for cataloguization and organization of library holdings.

4 Moodle 0 Modular Object-Oriented Dynamic Learning Environment, LMS = Learning Management System 
Moodle application is not driven from a local computer but from the institution's server, and the application itself is accessed from a local computer. However, there is also the possibility to install and run Moodle application on one's own computer. This possibility is crucial for a beginner, since it allows the user to first try and test application's possibilities and to acquire knowledge of the way of its use before installing the application on the institution's server (Cole and Foster, 2007, 1-21).

\section{Online classes in Moodle LMS}

The distinctiveness of Moodle LMS is reflected in its reliance upon the theory of social constructivism as a theory of learning, which allowed teachers to use teaching methods in the educational distance managed process using Moodle LMS. Web application Moodle LMS has a wide spectrum of possible use in all forms and at all levels of education aimed at managing distance learning and teaching processes. Moodle designers endeavored to create an array of learners' activities.

Moodle LMS is one of the most popular platforms designed for distance learning. Moodle's basis on educational theory and its orientation toward learning and teaching processes rather than toward used technology prompted me to direct attention to Moodle LMS and possibilities for teaching in online classes in music education, more accurately in musical culture classes.

Moodle LMS is an open source project, which means that users are allowed insight into the source, with the possibility to change the application and adjust it to their own needs (Cole and Foster, 2007, 11). The application can be downloaded free of charge from the official Moodle website (Moodle, 2012).

Web application Moodle LMS has a wide spectrum of possible use in all forms and at all levels of education aimed at managing distance learning and teaching processes. In this paper, I would like to present a way in which such an application can find its use in online classes in music education, actually in the classes on musical culture, and the possibilities for managing learning and teaching processes in the conditions when lecturers and students are separated in geographical and temporal sense.

\section{Prerequisites for successful use of online classes in Moodle LMS}

Before I began to present and describe learning modules and tools, and to analyze the possibilities of using the described learning modules and tools of Moodle LMS in online classes of musical culture, it was necessary to acquire the knowledge needed for programming in various program and server languages, 
as well as to know work with server technology and many other applications designed for coding, programming, graphics, multimedia and video design.

For Moodle LMS practical use in online classes, the teacher is required to have a high degree of competence and knowledge; both professional and didactic, as key competences, and those pertaining to the knowledge, use and management of web and server technologies, educational technologies, knowledge of and programming in various program and server languages, knowledge of the administration system and of work in several software applications.

Therefore, teachers and students must be IT literate, know how to use information technologies and network resources, be familiar with server technology and many other applications designed for coding, programming, graphics, multimedia and video design to be able to participate in online classes in Moodle LMS. Successful online classes in Moodle LMS is based on the systematic and joint work of students, teachers, assistants, administrators, support staff and organizational conditions for the implementation of Moodle LMS.

Organizational conditions for the Moodle LMS implementation can be classified into educational and technological ones.

The category of educational conditions include:

- adopting distance learning as a regular way of learning/studying in given institution,

- ability to prepare teaching materials in line with technology of distance learning,

- ability to deliver classes,

- ability to control classes and learning quality, and

- ability to provide support to users and distance learning students.

The technological component of organizational conditions consists of:

- ability to use the required technology by students;

- sufficient degree of knowledge by technical staff in the educational institution, who will ensure the quality and permanent operation of all elements of technical conditions for the implementation of distance learning system;

- ability to respond quickly to technical breakdowns of the system (Cole and Foster, 2007, 1-9).

Besides educational and technological conditions, implementation of such a concept of classes requires both students' and teachers' motivation. Having these conditions met, we can practically present the possibilities and ways of delivering online classes in some contents of musical culture in Moodle LMS using the existing modules, learning tools, communication tools, etc. 


\section{Developing online classes in musical culture in Moodle LMS}

In order to gain a clear understanding and present the possibilities for developing, managing and assessing the online teaching process using the web application Moodle LMS, I decided to describe, present, and practically use one of several ways of developing, managing and assessing the online teaching process in Moodle LMS on the example of content of classes in musical culture in the general-education high school from the angle of teachers, students and system administrator. While dealing with these issues, I was faced with a number of challenges and difficulties in achieving one of the goals and tasks of this work. Studying the possibilities of teaching using an extremely complex application in terms of programming such as Moodle LMS required the possession of various competences, particularly those related to the use of web technologies.

After a year-long intensive work on gathering literature, learning programming languages, work with web technologies, as well as preparing, drafting and posting contents in musical culture on the web application Moodle LMS on the server of my own computer rather than on the school's one, I managed to successfully develop online classes in musical culture for second-grade students of Cambridge International School in the First Bosniak General-Education Secondary School. The first and essential reason for selecting this content is that classes in musical culture proceed according to a reduced curriculum.

Implementation of online classes in Moodle LMS is one of the opportunities for students to adopt all teaching contents provided for by the Curriculum for musical culture rather than the reduced curriculum. Therefore, my intention was to use a selection of content for developing online classes to show the way in which we can additionally enrich the existing contents of musical culture that deal with distance learning and teaching, modern and up-to-date knowledge in this area. The contents I used when developing online classes as learning resources, are the contents that in regular classes of an hour per week are not supposed to be dealt with in-details .

For online classes in Moodle LMS, one should design a plan and mode of using modules process and procedures for developing and delivering classes in musical culture in high school, and learn how to use Moodle LMS from the viewpoint of teachers, students and system administrator. In the course of online classes, I have turned my own computer into a web server, to which I transferred the developed content of online classes and the entire Moodle, to allow students' access to online classes. I also installed and ran the version Moodle 1.9.19+ on my computer, at the address http://localhost/moodle. The same developed content of online classes and the entire Moodle should be transferred to the main web server, which we access from our own computer, or server should be installed on one's own computer. 
I have accessed online classes in musical culture in Moodle LMS, at the address http://onlinenastava.mk.ba, as the system administrator, course developer, teacher, student, with the user name and password and also as a guest (unauthenticated user) who does not need a user name and password. Every student received the user number and password from the administrator, for their own access to Moodle LMS.

Activities that we want to complete in an online course must be planned and elaborated in advance. For developing musical culture online classes in the high school, I have planned the entire online classes' course in advance. Presentation and distribution of static contents or learning resources were parts of the plan. This implied posting texts, graphics, video and audio recordings that would be used as the basis of content we would teach in musical culture online classes.

The official site of the Moodle LMS version that I have used for developing and delivering online classes contains six static modules designed for content distribution, as follows: heading, textual page, web page, link to another file or external website, directory, and the IMS package. Using each of the listed modules we can present contents or learning resources to students.

The kind and amount of material and the teaching method determine which of the listed modules should be used as a means of distribution. We can present contents for classes in musical culture using all the six modules. For presenting contents I selected two: the module of heading, and the web page module. I used the heading module for posting information on the course in simply formatted text for students (short announcements and instructions), and the web page module, which allows richer text styling and formatting, as well as inserting graphics, video, sound, animation, flash and links in the text. The essential reason for selecting this module is that it allows us to format the inserted contents as we wish and to enrich it with graphic elements - which we could not simply do using the online text module, while additional reason was the need for presentation of extensive contents.

Most Moodle modules are developed in line with principles of the theory of social constructionism as the theory of learning. Therefore Moodle modules, and particularly the dynamic modules, both require and support collaborative learning and interaction. The primary intention of the modules, i.e. learning tools in the Moodle system is to facilitate and improve learning. Moodle learning tools enable teachers to use teaching strategies in online teaching processes. The modularity of Moodle offers extensive possibilities for using various teaching methods. We use models in the Moodle system as means of organizing, moderating and assessing educational activities in online educational environments.

Several learning tools were used for developing online classes in musical culture, and the selection and the manner of using a tool depended on the kind of subject matter planned at the given moment, as well as on the point in time in 
the online course "distance learning and teaching". Based on the above criterion, the online classes utilised the following dynamic modules or learning tools: database module, forum module, chat module, lecture module, glossary module, assignment module and test module (Cole and Foster, 2007, 70-103).

The point in time of module opening was defined, while the final module point was pre-defined with the date of closing our online course. Thus, in the first week, for developing the online classes I used the database module, lecture module, glossary module, assignment module with essay-type questions, and test module. In the second week, I used the database module, lecture module, glossary module, forum module and test module. In the third week, I used glossary module and chat module, while in the last week I used database module, lecture module, glossary module, forum module, survey module and test module.

All activity modules or learning tools shall not be developed as separate and independent modules. The modularity of Moodle allows us the development of a unique whole where its elements (modules) will communicate with each other.

\section{Application of online classes in musical culture in Moodle LMS}

Moodle system allows us to organize educational activities of a course thematically and chronologically, with five different course formats: LAMS, SCORM $<$ Social, Thematic, Weekly format, and Weekly format without the SCC tabular formatting. The course format to be applied depends on following: the nature of the subject matter taught, teaching method used, defined goals and tasks of online classes, the number of students in online classes, course duration and many other factors (Cole and Foster, 2007, 20-25). I created classes in musical culture for students of the second grade at a general-education high school, and selected the type of the course that I considered the most appropriate for such content and the educational activities in "distance learning and teaching". The entire online teaching process of the course proceeds in Moodle. It is also the reason why Moodle LMS is often called a courseware. Moodle allows the creation of course categories, super-categories and meta-courses. Based on these factors, I decided to create the course "distance learning and teaching" in the thematic course format and to define the course duration at four weeks. For the first week of our online course I selected and prepared contents for the teaching on topic of "Musical art in the age of Renaissance in Italy in the $16^{\text {th }}$ century". For the second week of the course, contents for the teaching topic "Works of George Friedrich Handel, and Johann Sebastian Bach" were prepared. The topic for the third week was "Works of Wolfgang Amadeus Mozart and Ludwig van Beethoven", while in the fourth week we focused on the topic "Folk music tradition of Bosnia and Herzegovina". The topics I selected and prepared for online classes according to the curriculum for musical culture for general-education high schools are scheduled for the first 
semester. Online classes in Moodle LMS was developed for students who, upon participating in a survey where goals, tasks, duties, possibilities and advantages of online classes in Moodle LMS, voluntarily accessed online classes. Out of 20 surveyed students, 10 of them agreed to attend, which is sufficient for an experimental group. ${ }^{5}$

I distributed our educational activities in the thematic format by topics or thematic units (Figure 1). I did not limit the time for activities related to a thematic unit in the thematic format of the course, thereby allowing students to set their own pace of learning within 30 days scheduled for the course. In this course, I also selected the possibility for students to return to the already completed teaching units later, if they need it. However, I have clearly limited the time for some educational activities. In this way we allow students to use learning resources as teaching content, while we prevent them from abusing the possibility for re-using static contents by defining the dates of beginning and end of a given educational activity. At the very entrance to the online course, we created a short summary about what students can expect over the four weeks of online classes. In the summary, we also noted the possibility of assessing students' activities and that the grade they achieve in this online course is part of the final grade achieved in the end of the actual semester. The text of the summary is available at the very entrance to the online course, as well as its content, which students can see when accessing online classes. As the system administrator, I assigned user roles in the course. More accurately, I defined the user who will have the teacher's role in the course, the user in the role of system administrator and users with students' roles (Cole and Foster, 2007, 49-57).

5 We delivered online classes in musical culture in Moodle LMS at Cambridge International School at the First Bosniak General-Education High School in the first semester of 2012/2013 academic year (from 24. 11. to 24. 12. 2012). 


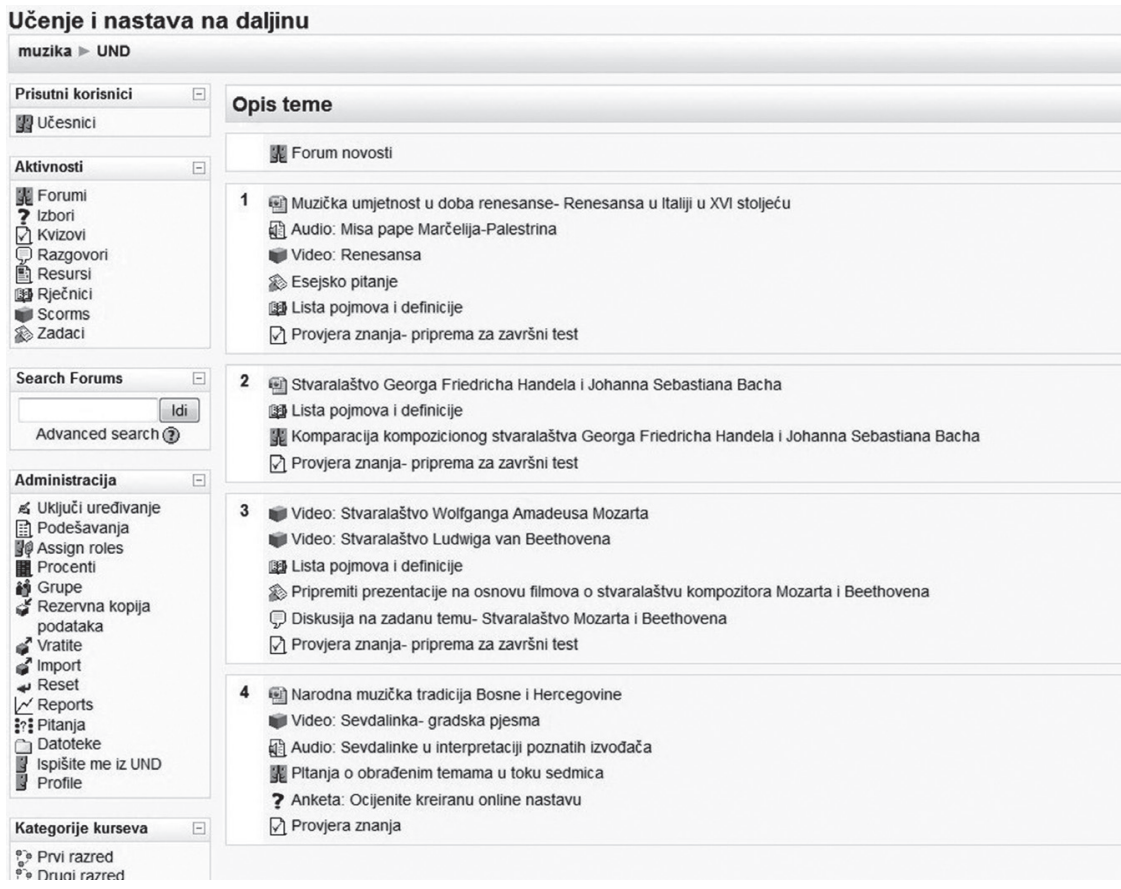

Figure 1: Course site with all elements for online course in musical culture ${ }^{6}$ (Idego, 2012)

\section{Possibilities of Moodle LMS in online classes of musical culture}

Continuous communication with students is an essential prerequisite for success. Moodle LMS distance teaching and learning applied in the musical culture classes at high school primarily emphasized the individualized approach to students, which can be achieved only in the close relationship with the awareness on students' personalities, their psychophysical abilities, way of work and success they have achieved in their previous work. Students have positively assessed the motivating aspect of such a form of education, reporting that it helped them sufficiently or a lot in mastering and supplementing the subject matter and in preparations for the final assessment.

It is essential that Moodle is user friendly. Contents posted in Moodle LMS should be continuously built upon with changes and innovations in content, methodology, while communication efficiency and content adjustability to different learning strategies should continuously be improved. A crucial segment of successful functioning of the whole system includes the construction of

${ }^{6}$ Screenshot sajta kursa. Sajt kursa bio aktivan trideset dana za vrijeme trajanja online nastave, datum posjete: 16. 11.2012. 
knowledge assessment system, from self-assessment to final assessment of each educational unit. In order to achieve the best efficiency possible, all means that encourage students' work and advancement should be used. For each educational unit, it is necessary to design and clearly define learning results, so that students can have a clear picture of what is expected from them. Methods of knowledge assessment should be adjusted to learning performance, since they encourage different learning strategies.

After the completion of four-week online classes in which students of the experimental group studied teaching contents of musical culture in Moodle LMS online classes, while students of the control group studied contents in regular classic classes using other technologies according to the reduced curriculum, both groups of students were administered the final knowledge assessment test.

The aim of the testing was to determine how much the experimental group students advanced in this period and whether there were differences in achieved results between students of the two groups. The obtained test results reveals that students of the experimental group, after learning the content of musical culture in online classes in Moodle LMS along with the regular in-class classes, have achieved better results compared to the control group.

In the test, the experimental group students showed both good results, i.e. a higher number of points, and that they have acquired greater knowledge in the same content studied by the control group students. Their responses to test questions were on a higher level. To each question, the experimental group students responded correctly, with their own interpretation and more information. In the responses to questions in the final test, students of experimental group showed both better results and better knowledge.

The final test proves that use of online classes in Moodle LMS has its advantages. Besides the classic classes, using appropriate teaching methods, Moodle system modules, with interaction among students and timely feedback between the teacher and students in a high-quality, flexible and creative way; without an additional burden, students can adopt all the contents provided for by the curriculum of Musical culture for high schools of the Sarajevo Canton. Students who participated in online classes in Moodle LMS in musical culture had a positive opinion and views of the new way of working and learning.

\section{Conclusion}

The research conducted with the aim of gaining clearer understanding and presenting the possibility of developing, managing and evaluating the online teaching process using the web application Moodle LMS in teaching musical culture in the general-education high school reveals that distance learning can be equally successful as the traditional classes, if appropriate methods and 
technologies are used, if there in interaction among students and timely feedback between the teacher and students.

By using Moodle LMS, students play an active role in the education process. Every activity in Moodle LMS is recorded and later serves for assessing students' work and success. Knowledge self-assessment allows students to evaluate the level of acquired knowledge, and indicates to the teachers an individual's activity or advancement through testing in certain time intervals.

We must make distance learning a detaching meaningful and directly applicable in reality, which results in a high level of processing the information obtained in the learning process. By structuring knowledge for others we learn ourselves. Distance learning and teaching are interactive, collaborative, it provides the teacher and students with the experience of group learning, learning from others, which allow students to use and develop metacognitive skills.

The first and main reason for choosing this kind of classes is that classes in musical culture for second-grade students of Cambridge International School in the First Bosniak General-Education High School proceed according to the reduced curriculum.

Implementation of online classes in Moodle LMS is one of the possibilities for students to adopt all the contents provided for by the curriculum for musical culture, rather than by the reduced curriculum. Therefore, our intention was to use the selection of contents for developing online classes to show in which way we can additionally enrich the existing contents of musical culture that involve distance learning and teaching with modern and up-to-date insights in the area.

Online classes are an active process requiring students to apply the information that facilitates their own interpretation and importance. Good interactive online classes facilitate the creation of knowledge, since students must take initiative to learn and be in interaction with other students and the instructor, while controlling their daily learning schedule by themselves. In online educational environment, students receive information firsthand, rather than receiving information filtered by the instructor, whose style may be different from theirs. Through online classes students experience information firsthand, which allows them to contextualize and personalize information themselves.

\section{References}

Cole, J. and Foster, H., 2007. Using Moodle, 2nd Edition Teaching with the Popular Open Source Course Management System. USA: Publisher O’Reilly Media. Guthrie, W., J. ed., 2002. Encyclopedia of Education. USA: Macmillan Reference Library.

Idego d.o.o., 2012. Moodle online učionica. Available at: <http://nastava.ba/ moodle-online ucionica/> [Accessed 16 November 2012]. 
Kljakić, D., 2006. Internet u funkciji učenja. Naša škola, LII (36), 3-23.

Moore, M. G. and Anderson, W. G. eds., 2003. Handbook of Distance Education. New Jersey: Lawrence Erlbaum Associates, Inc.

Porter, L., L., 2004. Developing an Online Curriculum: Technologies and Techniques, London: Embry-riddle Aeronautical University, Information Science Publishing

Tinio, L., V., 2002. ICT in Education, New York: United Nations Development Programme Bureau for Development Policy Moodle, 2012. Moodle downloads. Available at: <http://download.moodle.org/> [Accessed 23 May 2012]. 